\title{
Pilot study examining tumor expression of RAD51 and clinical outcomes in human head cancers
}

\author{
PHILIP P. CONNELL ${ }^{1}$, KRISHANTHI JAYATHILAKA ${ }^{1}$, DANIEL J. HARAF ${ }^{1}$, \\ RALPH R. WEICHSELBAUM ${ }^{1}$, EVERETT E. VOKES $^{2}$ and MARK W. LINGEN ${ }^{1-3}$ \\ Departments of ${ }^{1}$ Radiation and Cellular Oncology, ${ }^{2}$ Medicine, and \\ ${ }^{3}$ Pathology, University of Chicago, Chicago, IL 60637, USA
}

Received November 11, 2005; Accepted December 20, 2005

\begin{abstract}
Radiation therapy and chemotherapy are commonly used treatments for head and neck cancer. RAD51 is a highly conserved DNA repair protein that serves a central function in the homologous recombination pathway. High levels of RAD51 protein expression have been reported in number of human cancer cell lines, and studies suggest that RAD51 overexpression can increase cellular resistance to radiation and some chemotherapeutic drugs. In this study, RAD51 protein levels were quantified by immunohistochemistry in tumor samples from twelve head and neck cancer patients who received identical treatment with induction chemotherapy (paclitaxel and carboplatinum) followed by radiation therapy given concurrently with additional chemotherapy (paclitaxel, fluorouracil, hydroxyurea). Patients with high RAD51 protein levels in their pre-treatment tumor biopsies demonstrated poorer cancer-specific survival rates than patients with lower RAD51 levels (33.3\% vs. $88.9 \%$ at 2 years; $p=0.025)$. In addition, within a subgroup of patients with normal tumor cell p53 expression, there was a non-significant trend toward better induction chemotherapy response rates observed in the tumors with lower RAD51 protein levels. These results suggest that tumor cell RAD51 expression levels may influence the outcome of patients with head and neck cancer treated with chemotherapy and radiotherapy.
\end{abstract}

\section{Introduction}

RAD51 is a highly conserved well-characterized DNA repair protein that has a central role in the homologous recombination (HR) pathway. Prokaryotic and eukaryotic cells defective in HR are sensitive to DNA cross-linking agents and ionizing radiation (1-4). By contrast, up-regulation of HR can render

Correspondence to: Dr Philip P. Connell, Department of Radiation and Cellular Oncology, University of Chicago Hospital, 5758 S. Maryland Ave., MC 9006, Chicago, IL 60637, USA

E-mail: pconnell@rover.uchicago.edu

Key words: DNA repair, homologous recombination, molecular markers, head and neck tumors, RAD51 cells more resistant to DNA damaging agents (5). Several studies have shown RAD51 protein expression levels to be elevated in immortalized cells and a wide variety of human cancer cell lines (6-8). A growing body of literature suggests that RAD51 overexpression can increase cellular resistance to radiation and some chemotherapeutic drugs (8-13). There are only a few studies that have investigated RAD51 expression levels in human tumors. These immunohistochemical (IHC) analyses demonstrated RAD51 overexpression in human breast, bladder, pancreatic, and lung tumors (13-18). A recent study of lung cancer patients reported poor prognoses for patients with tumors that strongly express RAD51 (18).

Epithelial cancers of the head and neck are frequently treated with radiotherapy and with chemotherapeutic agents that mediate cell killing by cross-linking DNA. Many proteins have been studied in order to identify markers that predict sensitivity or resistance to DNA damaging agents, although to date no single molecular marker can reliably predict response to radiotherapy or chemotherapy. A predictive biomarker would improve clinical treatment decisions, thereby allowing physicians to tailor the types, doses, and sequencing of therapies to specific patients. This approach may also help to eliminate potentially toxic therapies deemed to have low expected benefits.

In the present study, RAD51 protein expression was investigated in tumors from patients with epithelial cell cancers of the head and neck. All patients were identically treated with induction chemotherapy (paclitaxel and carboplatinum) followed by radiation therapy given concurrently with additional chemotherapy (paclitaxel, fluorouracil, hydroxyurea). Patients with high RAD51 levels in pre-treatment tumor biopsies experienced inferior survival compared to patients with lower RAD51 levels. In addition, within a subgroup of patients with normal tumor cell p53 expression, there was a trend toward better induction chemotherapy response rates observed in the tumors with lower RAD51 protein levels. These results suggest that tumor cell RAD51 expression levels may influence the outcome of patients with head and neck cancer treated with chemotherapy and radiotherapy.

\section{Patients and methods}

Patients and treatment. Records and tissue samples were retrospectively analyzed from twelve patients that had previously 
Table I. Clinical characteristics of patients and tumors. ${ }^{\mathrm{a}}$

\begin{tabular}{ccclcccccc}
\hline Patient no. & Sex & $\begin{array}{c}\text { Age } \\
\text { (years) }\end{array}$ & Site & $\begin{array}{c}\text { Tumor } \\
\text { stage }\end{array}$ & $\begin{array}{c}\text { LN } \\
\text { stage }\end{array}$ & FTV & $\begin{array}{c}\text { RAD51 } \\
\text { staining }\end{array}$ & $\begin{array}{c}\text { p53 } \\
\text { staining }\end{array}$ & $\begin{array}{c}\text { PCNA } \\
\text { staining }\end{array}$ \\
\hline 1 & M & 67.2 & BOT & 2 & 3 & 1.04 & $3+$ & Negative & Strong \\
2 & M & 45.1 & PS & 4 & $2 \mathrm{c}$ & 0.82 & $1+$ & Focal & Strong \\
3 & M & 56.3 & SGL & 4 & $2 \mathrm{a}$ & 0.81 & $3+$ & Negative & Strong \\
4 & M & 44.8 & SGL & 2 & $2 \mathrm{~b}$ & 0.63 & $2+$ & Negative & Strong \\
5 & M & 67.0 & SGL & 4 & 1 & 0.63 & $2+$ & Negative & Strong \\
6 & M & 62.4 & Larynx & 4 & 3 & 0.41 & $2+$ & Focal & Strong \\
7 & F & 48.4 & SGL & 4 & $2 \mathrm{c}$ & 0.41 & $3+$ & Diffuse & Strong \\
8 & M & 56.6 & BOT & 4 & $2 \mathrm{a}$ & 0.35 & $1+$ & Diffuse & Strong \\
9 & M & 58.3 & Tonsil & 3 & 3 & 0.27 & $1+$ & Focal & Strong \\
10 & F & 66.7 & FOM & 2 & $2 \mathrm{c}$ & 0.24 & $2+$ & Diffuse & Strong \\
11 & M & 54.4 & Tonsil & 2 & $2 \mathrm{~b}$ & 0.17 & $2+$ & Focal & Strong \\
12 & F & 66.3 & BOT & 1 & $2 \mathrm{~b}$ & 0.06 & $3+$ & Diffuse & Strong \\
\hline
\end{tabular}

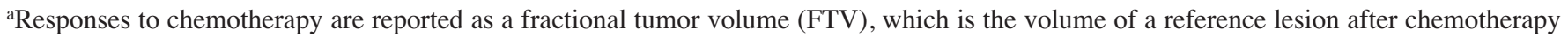
divided by the pre-chemotherapy volume. BOT, base of tongue; PS, pyriform sinus; SGL, supra-glotic larynx; LN, lymph node; FOM, floor of mouth; PCNA, proliferating cell nuclear antigen.

completed treatment for non-metastatic regionally advanced squamous cell carcinomas of the larynx, pharynx, or oral cavity. All patients had stage-IVA or -IVB disease, based on the current staging rules of the American Joint Committee on Cancer (AJCC). Treatments consisted of induction chemotherapy followed by concomitant chemoradiotherapy. The induction regimen consisted of 2 monthly cycles of paclitaxel (100 mg/m $\mathrm{m}^{2}$ on weeks 1,2 , and 3 of each cycle) and carboplatin (AUC 6 on week 1 of each cycle). This was followed by concomitant chemoradiotherapy consisting of paclitaxel, fluorouracil, hydroxyurea and hyperfractionated radiotherapy. This regimen has been previously described in detail (19).

All patients provided written informed consent for use of records and tissue for research purposes when enrolling on this treatment protocol. A separate protocol detailing the analysis via RAD51 staining was approved by the University of Chicago Institutional Review Board (IRB) and Cancer Trial Review Committee. The total number of patients treated according to the aforementioned clinical trial was considerably larger than the twelve analyzed in the current study. Because of potential ethical concerns surrounding the use of human tissue, only twelve subjects were selected for the present pilot IHC analysis. Patients were selected for inclusion based on clinically judged tumor response rates to the induction chemotherapy portion of treatment. Four patients were selected for each category of chemotherapy response: poor (progressive or stable disease), intermediate (partial response), and excellent (near complete response). The clinical characteristics of the patients and tumors are detailed in Table I.

Immunohistochemical techniques. All tumor tissue was taken from archived pre-treatment paraffin-embedded biopsy specimens. IHC for RAD51 was performed using previously published methods and reagents (15) with some modifications. Microscope slides were prepared with $4 \mu \mathrm{m}$-thick sections, deparaffinized, and processed for antigen retrieval via micro- wave in a citrate buffer. Slides were then incubated with primary anti-RAD51 antibody (1:1,000; Calbiochem, La Jolla, CA) for $1 \mathrm{~h}$, followed by a biotinylated secondary antibody, followed by streptavidin-peroxidase complex (Dako, Carpinteria, CA). Colored products were produced using a diaminobenzidine substrate. The intensity of staining (1+ to 3+) was scored for each slide by a board-certified oral pathologist (M.W. Lingen), who was blinded to all related clinical information, and was further quantified using a positive-stained cell index (PCI), which represents the portion of cells that are strongly stained. The scoring of cells was based on nuclear staining only, and PCI was calculated for each slide via manual counting of 200 randomly selected cells. For determination of cell proliferation, sections were microwaved in citrate buffer and incubated in a 1:1 dilution of PCNA antibody (Zymed, San Francisco, CA). For detection of p53 expression, sections were incubated with primary anti-p53 antibody (1:100; Labvision/Neomarkers, Fremont, CA) followed by a biotinylated secondary antibody, followed by streptavidin-peroxidase complex (Dako). Scoring of PCNA and p53 expression was performed as previously described (20).

Measurements of response. The tumor response rates were determined based only on the induction chemotherapy portion of treatment. Contrast-infused CT scans were performed before treatment and after the second cycle of chemotherapy. A reference tumor lesion (primary tumor or lymph node) was selected for measurement in each patient. Tumors that were amenable to clear and reproducible measurement on CT were selected as reference lesions. For example, diffusely infiltrating tumors in the tongue base can be difficult to clearly delineate, whereas encapsulated lymph nodes tend to be very suitable for measurement. Each reference lesion was contoured on a sliceby-slice basis, and tumor volume was calculated using the AcuSim software package (Siemens). Fractional tumor volume (FTV) was calculated based on post-chemotherapy reference 

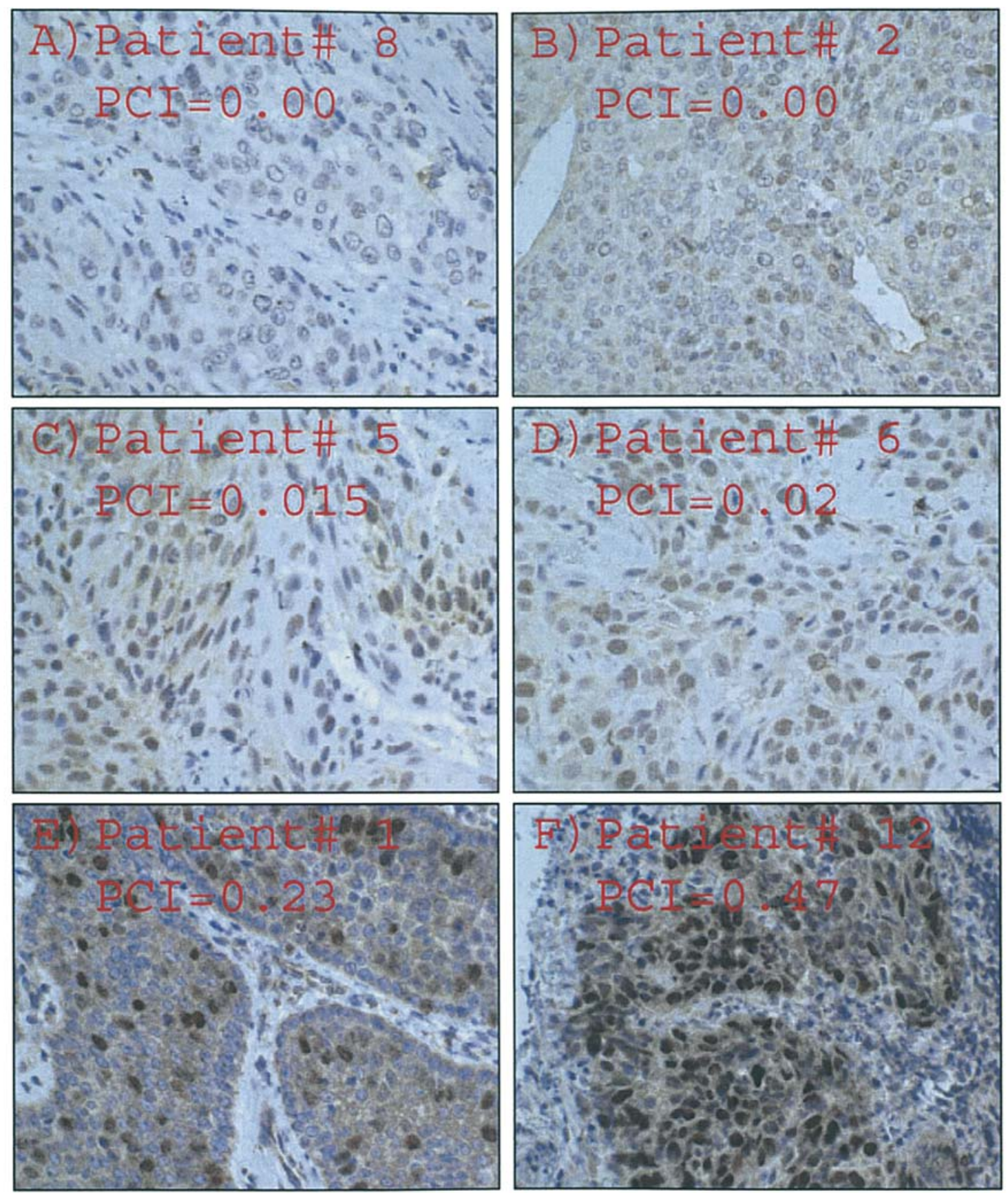

Figure 1. High magnification staining patterns of RAD51 in squamous cell carcinomas of the head and neck. Representative images are displayed from specimens with low (1+) nuclear staining (A and B), moderate (2+) nuclear staining (C and D), and high (3+) nuclear staining (E and F). PCI, positive staining cell index.

tumor volume divided by pre-chemotherapy reference tumor volume.

Statistical considerations. Statistical analyses were performed with the Stata 9.0 software package (College Station, TX). Fisher's exact test was used to test for relationships between RAD51 staining and other clinical/pathological variables. Linear regression analysis was performed to test for correlations between the continuous variable FTV and RAD51 staining (as PCI). Follow-up intervals were calculated from the date of diagnosis. Actuarial cancer-specific survival curves were calculated using the method of Kaplan-Meier and compared with the log-rank test.

\section{Results}

Head and neck tumor tissue was analyzed by IHC to determine the patterns and intensities of RAD51 staining (Table I and Fig. 1). The majority of RAD51 staining in tumors was nuclear, although some cytoplasmic staining was noted. RAD51 is a protein which executes its known function on DNA repair; therefore, we quantified nuclear staining only. Four tumors had intense (3+) staining, five had moderate (2+) staining, and three had low (1+) staining. In most specimens, the positively stained cells were distributed across the tumor tissue, although in one specimen the positive cells were clustered (Fig. 1F). To provide a finer range of results, the 

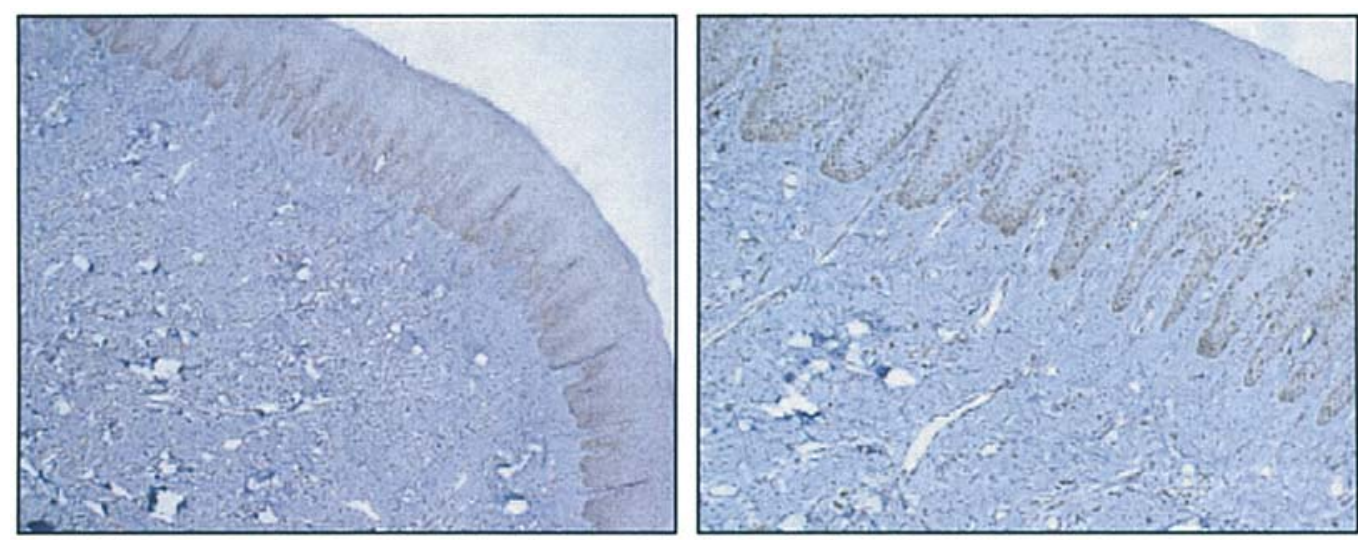

Figure 2. Representative RAD51 staining patterns in normal human head and neck biopsies. IHC staining is shown in low magnification (left) and medium magnification (right).

Lateral DRR:

Pre-Treatment

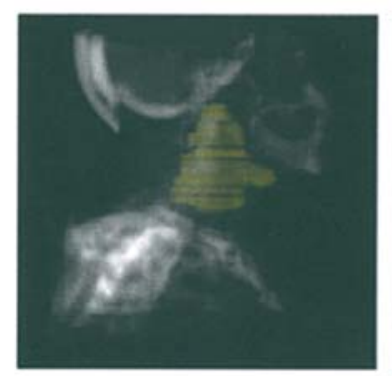

Patient \#1 FTV $=1.04$

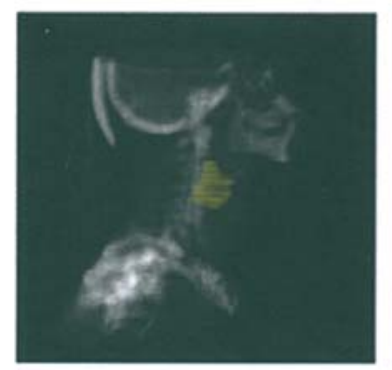

Patient \#4 FTV $=0.63$

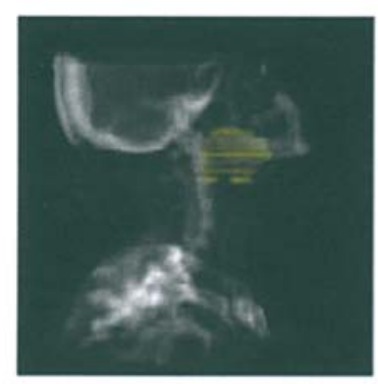

Patient \#8 FTV $=0.35$

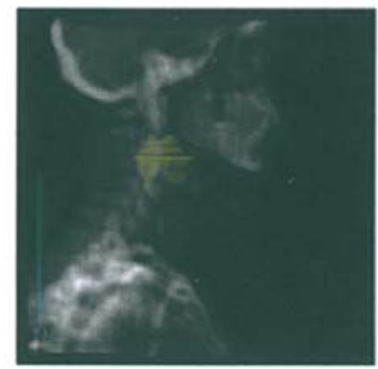

\section{Post-Treatment}
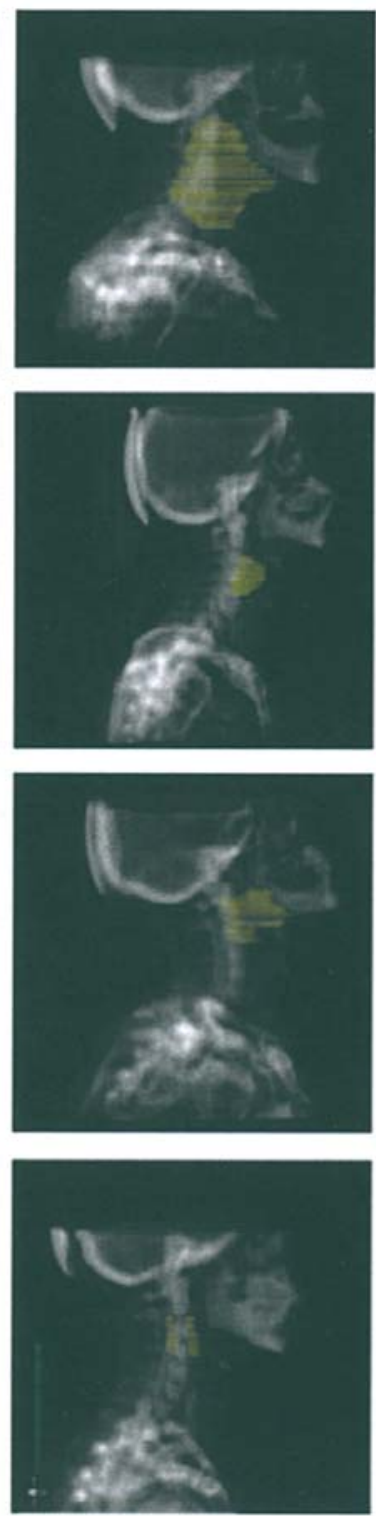

Axial Image:

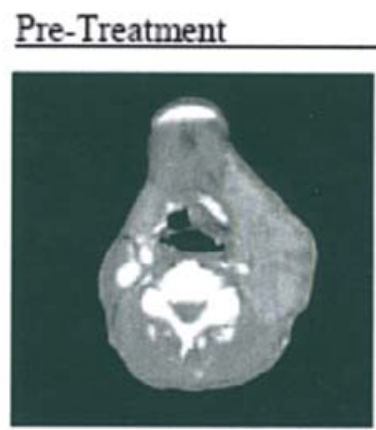

Post-Treatment
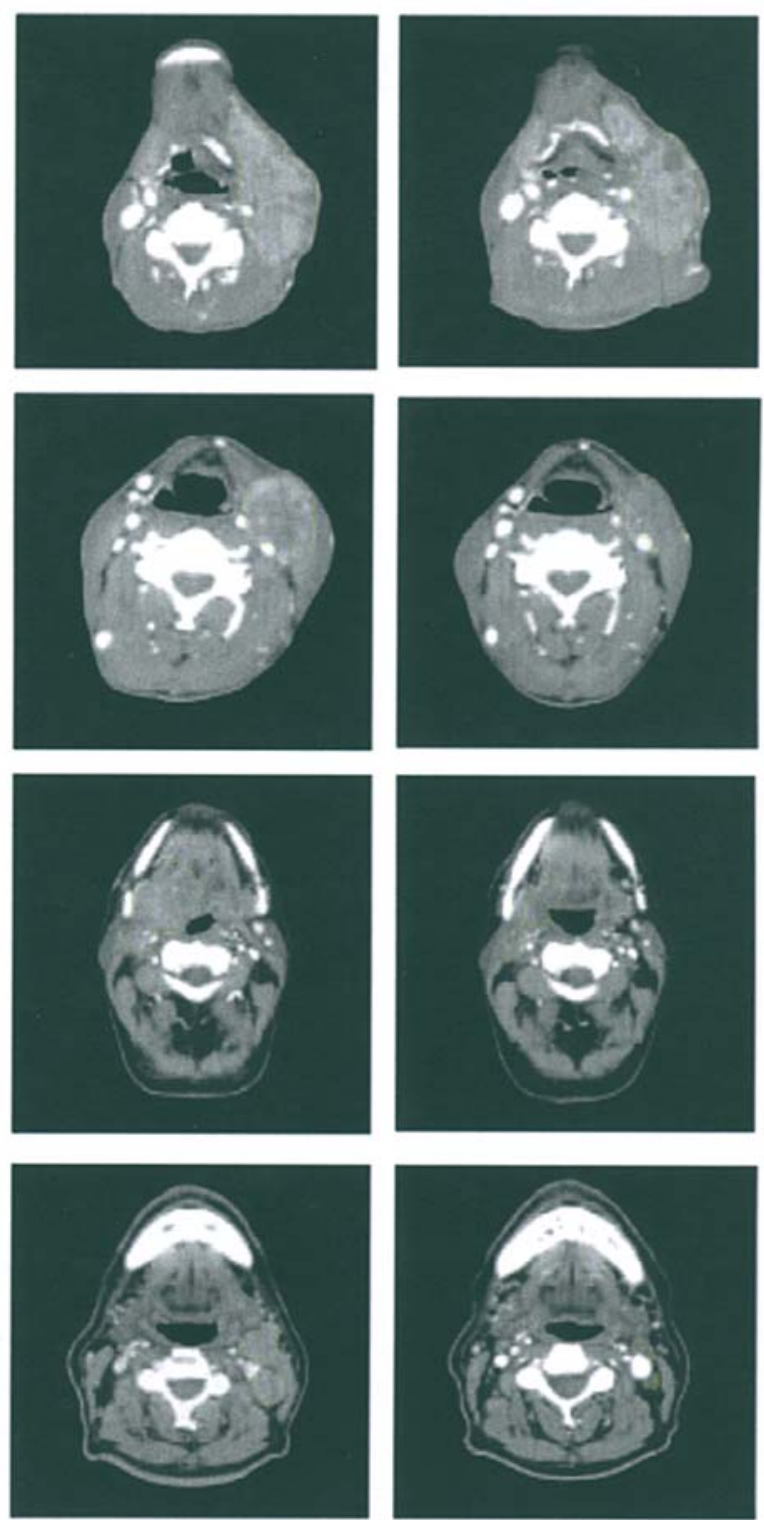

Figure 3. Images of tumors from four representative patients. Reference tumors (pre- and post-chemotherapy) are represented in yellow, and are displayed in panels with laterally-oriented digitally reconstructed radiographs (DRR) on the left and with axial CT images on the right. 
slides were also scored with a positively-stained cell index (PCI), which was defined as the portion of cells with strong nuclear staining. The standard scoring method $(1+$ to $3+)$ and PCI method agreed well. Four specimens had intense PCI's (0.06-0.465), five had moderate PCI's (0.015-0.05), and three had a low PCI (0). By contrast, IHC analysis of tissue from a normal human oral mucosal biopsy showed nuclear staining, primarily of the basal cell layer and, to a lesser extent, of the nuclei throughout the stratified squamous layer (Fig. 2). The nuclei of some inflammatory cells with the sub-mucosal connective tissue also stained positively. The intense suprabasal staining pattern of normal mucosa looked similar to previously reported RAD51 staining in epidermal squamous epithelium (17).

Since RAD51 expression may be, in part, a function of tumor cell growth rate, the tissue was also tested via IHC for proliferating cell nuclear antigen (PCNA), a protein associated with DNA replication and repair. All of the tumor specimens exhibited equally strong staining for PCNA; therefore, the RAD51-related results appear to be, at least partially, independent of tumor proliferation rates. However, we cannot exclude the possibility that more subtle proliferative differences exist and are beyond our limits of detection with PCNA staining. Tumor tissue was also processed via IHC to detect abnormalities in p53, a commonly studied biomarker in head and neck cancer $(21,22)$ that may play a role in modulating HR $(23,24)$. Most $p 53$ gene mutations result in aberrant p53 proteins with abnormally long half-lives; therefore, strong staining of $\mathrm{p} 53$ protein via IHC is a common surrogate marker for mutations. Four specimens had negative staining, four had focally positive staining, and four had strongly positive staining. There was essentially no correlation observed between p53 and RAD51 staining results $(\mathrm{p}=0.355)$. There were also no significant correlations noted between RAD51 staining and any of the clinical variables, including age, $\mathrm{T}$ stage, $\mathrm{N}$ stage, or sex.

Following induction chemotherapy, patients received further treatment with concomitant chemoradiotherapy \pm surgery. After completing all treatments, all patients had complete disappearance of measurable disease and were followed for a median interval of 36 months (range, 8.3-50.6 months). Six patients died during this time, and three of the six patients suffered cancer recurrences and died secondary to their cancer. Two of these three patients had pre-treatment tumors with 3+ RAD51 staining (PCI's of 0.27 and 0.225 ). When high RAD51 staining was defined as PCI $\geq 0.1$, inferior actuarial cancer-specific survival rates were observed in the three patients with high PCI values compared to the nine patients with low PCI values $(33.3 \%$ vs. $88.9 \%$ at 2 years; $\mathrm{p}=0.025$ log-rank).

The IHC results were also compared with radiographic tumor response rates, to determine whether RAD51 overexpression is associated with resistance to platinum-based chemotherapy. CT scans of the head and neck were performed on each patient before and after induction chemotherapy (two cycles of paclitaxel and carboplatin). For each patient, a reference tumor mass was selected for volumetric measurement (Fig. 3). Fractional tumor volume (FTV) was calculated for each patient, which was defined as post-treatment reference tumor volume divided by pre-treatment reference tumor

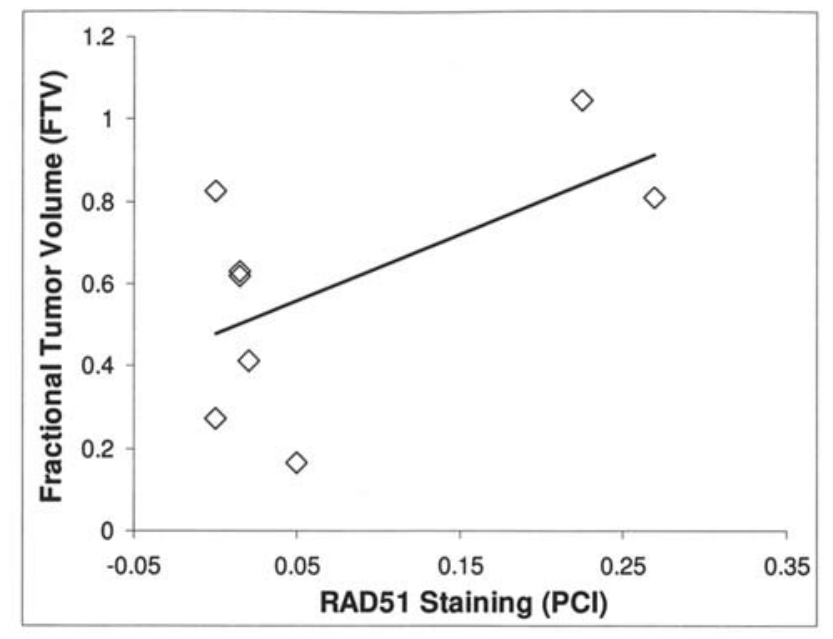

Figure 4. Correlation between RAD51 staining and tumor responsiveness after platinum-based induction chemotherapy. For this analysis, tumors with strong p53 staining have been censored.

volume. When all patients were included in the analysis, no clear trends were noted between RAD51 staining and FTV results. After the tumors with strong diffuse p53 staining were censored, however, a trend was observed between RAD51 staining and FTV (Fig. 4). Given the small number of patients analyzed, this trend did not reach statistical significance $(\mathrm{p}=0.128)$. However, within this sub-group, it is interesting that the two strongest RAD51 expressers had very poor tumor responses to chemotherapy (FTV's of 1.04 and 0.808 ).

\section{Discussion}

This is the first study to evaluate tumor expression levels for RAD51 protein in human squamous cell cancers of the head and neck. It is also the first study to compare RAD51 tumor levels with rigorously quantified clinical outcomes in a population of patients that have comparable stages and identical treatments. Our results provide evidence of significantly inferior long-term cure rates in patients that have tumors with high RAD51 levels. This study also demonstrates a trend between RAD51 expression levels and resistance to platinumbased chemotherapy in tumors with normal p53 status.

Several studies have described RAD51 overexpression in other types of human cancer. Maacke and co-workers demonstrated that $66 \%$ (27 of 41 ) of human pancreatic adenocarcinomas overexpress RAD51. The percentage of RAD51 positive tumor cells ranged from $5 \%$ to $50 \%$, depending on the specimen (13). This overexpression stimulates a B-cell response leading to RAD51-specific auto-antibodies found in the serum of $7 \%$ of patients with pancreatic tumors (25). Investigators at University of Arizona reported similar results, demonstrating RAD51 overexpression in $74.2 \%$ of human pancreatic tumor specimens. In fact, $12.9 \%$ of the tumors exhibited very strong staining (scored as $3+$ or more). The high protein levels corresponded with elevated RAD51 mRNA levels, suggesting transcriptional up-regulation (15). High RAD51 expression levels have also been observed in invasive ductal breast tumors, relative to normal breast tissue $(14,17)$. The percentage of RAD51-staining breast cancer cells was 
as high as $68 \%$ in some tissue specimens. Interestingly, the intensity of RAD51 staining correlated significantly with histological tumor grade (14).

We speculate that RAD51 overexpression leads to inferior tumor control rates by increasing repair of treatment-induced DNA damage. Alternatively, the poor tumor responsiveness could be an indirect manifestation of the genetic instability associated with HR disregulation (16). Few other studies have explored the clinical significance of RAD51 expression levels in human tumors. A study with papillary bladder carcinomas described a correlation between RAD51 overexpression and tumor progression; however, the details of this study are yet to be published (16). Qiao et al recently reported RAD51 staining results from 383 patients with surgically resected non-small cell lung cancer. Patients with high tumor RAD51 staining (defined as PCI >0.1) had a relatively poor median survival, and this result remained statistically significant after controlling for other prognostic variables, such as stage and histological grade. This effect was more prominent in patients with squamous cancers relative to adenocarcinomas. Information about adjuvant therapies was not available to the investigators, so no conclusions could be drawn regarding a potential role of RAD51 expression as a predictor of response to treatment (18).

Elevated RAD51 protein levels in tumor cells are thought to result from up-regulation at the transcriptional level $(15,16,26)$; however, the mechanisms responsible for this transcriptional up-regulation are not completely defined at present. Within non-malignant tissue, proliferating cells tend to express more RAD51 than do resting cells, and the timing of this expression peaks during the $\mathrm{S} / \mathrm{G} 2$ segments of the cell cycle $(27,28)$. Accordingly, one might expect to see relatively high RAD51 expression in rapidly growing tumors that contain a high portion of cells in S-phase. This idea is supported by an IHC analysis of human breast tumors which showed a direct correlation between the expression levels of RAD51 and the proliferation marker, Ki67 (14). However, a different study of chronic lymphocytic lymphoma (CLL) cells from seventeen patients showed no correlation between levels of RAD51 and PCNA proteins on Western blot analyses (12), indicating that RAD51 expression depends on factors other than growth rates alone. In our study, the RAD51-related results appeared to be, at least partially, independent of tumor proliferation rates. However, we cannot exclude the possibility of subtle proliferative differences that were beyond our limits of detection with PCNA staining.

Some investigators have suggested that RAD51 can be transcriptionally up-regulated as a result of oncogenic activation of c-Abl tyrosine kinase, which mediates its effect via a Stat5-dependent pathway. Chromosomal translocations that result in constitutively active fusion tyrosine kinase (FTK) proteins like Brc/Abl have been shown to elevate RAD51 expression via this mechanism $(10,11)$. In one such study, RAD51 expression levels in human cell lines were modulated by introducing various FTK proteins. All of the FTK's, except one, elevated RAD51 expression levels (5- to 8-fold) relative to the parental cell line. The RAD51 expression levels correlated with cellular resistance to cisplatin, and this resistance was partially reversed by blocking RAD51 expression with an anti-sense strategy (11). In another study, radiation-induced
RAD51 expression was reduced in a human glioma cell line using STI571 (Gleevec), which is a relatively specific inhibitor of the Abl kinase (29).

It's interesting that the trend between RAD51 levels and chemo-responsiveness appeared only when tumors staining strongly for p53 were censored. Alterations in the p53 gene are among the most commonly reported genetic events in head and neck cancer. RAD51 protein is also known to physically interact with wild-type p53 protein and, to a lesser extent, several of the p53 mis-sense mutants commonly seen in human cancers $(30,31)$. There is evidence that $\mathrm{p} 53$ protein can directly modulate HR function in vivo $(23,24)$. Therefore, abundant mutant $\mathrm{p} 53$ proteins observed in some tumors may have directs affects on RAD51 function. An alternative explanation is that p53 gene mutations simply generate severe independent phenotypes of their own, and that these outweigh the biological significance of RAD51 protein levels.

Based on these findings, it is tempting to speculate that HR could be targeted for inhibition in order to sensitize tumors to DNA damaging therapies. We previously reported that a synthetic peptide corresponding to RAD51C (a RAD51-related protein) sensitized Chinese Hamster Ovary (CHO) cells to cisplatin and inhibited the formation of sub-nuclear RAD51 foci in response to DNA damage (32). Other researchers have inhibited the expression of the RAD51 protein itself $(8,29$, 33-35) or blocked it's function by overexpressing a dominant negative BRC peptide fragment from BRCA2 (36). A targeted approach focusing on HR is particularly appealing, since several studies have suggested that HR inhibition preferentially sensitizes tumor cells relative to normal cells $(29,34)$. Therefore, this strategy holds promise for improving the therapeutic ratios of existing oncology treatments.

A limitation of our study is the small number of patients analyzed, and our results will need to be confirmed with a larger patient sample. Nonetheless, our data suggest that high levels of RAD51 expression predict poor long-term control rates and may predict tumor resistance to platinum-based chemotherapy.

\section{Acknowledgements}

The authors would like to thank Dr Maria Tretiakova and Ms. Leslie Martin for assistance with the processing of slides. We also wish to thank Ms. Mary Ellen Witt for work as clinical database manager and Mr. Richard Martin for critical review of the manuscript. This work was supported in part by funding from the American Society for Therapeutic Radiology and Oncology (ASTRO) Junior Faculty Fellowship Award (P.P.C.) and NIH grants, no. DE12322 and DE00470 (M.W.L.).

\section{References}

1. Tebbs RS, Zhao Y, Tucker JD, Scheerer JB, Siciliano MJ, Hwang M, Liu N, Legerski RJ and Thompson LH: Correction of chromosomal instability and sensitivity to diverse mutagens by a cloned cDNA of the XRCC3 DNA repair gene. Proc Natl Acad Sci USA 92: 6354-6358, 1995.

2. Liu N, Lamerdin JE, Tebbs RS, Schild D, Tucker JD, Shen MR, Brookman KW, Siciliano MJ, Walter CA, Fan W, Narayana LS, Zhou ZQ, Adamson AW, Sorensen KJ, Chen DJ, Jones NJ and Thompson LH: XRCC2 and XRCC3, new human Rad51-family members, promote chromosome stability and protect against DNA cross-links and other damages. Mol Cell 1: 783-793, 1998. 
3. Godthelp BC, Wiegant WW, van Duijn-Goedhart A, Scharer OD, van Buul PP, Kanaar R and Zdzienicka MZ: Mammalian Rad51C contributes to DNA cross-link resistance, sister chromatid cohesion and genomic stability. Nucleic Acids Res 30: 2172-2182, 2002.

4. Takata M, Sasaki MS, Tachiiri S, Fukushima T, Sonoda E, Schild D, Thompson LH and Takeda S: Chromosome instability and defective recombinational repair in knockout mutants of the five Rad51 paralogs. Mol Cell Biol 21: 2858-2866, 2001.

5. Wang ZM, Chen ZP, Xu ZY, Christodoulopoulos G, Bello V, Mohr G, Aloyz R and Panasci LC: In vitro evidence for homologous recombinational repair in resistance to melphalan. J Natl Cancer Inst 93: 1473-1478, 2001.

6. Xia SJ, Shammas MA and Shmookler Reis RJ: Elevated recombination in immortal human cells is mediated by HsRAD51 recombinase. Mol Cell Biol 17: 7151-7158, 1997.

7. Raderschall E, Stout K, Freier S, Suckow V, Schweiger S and Haaf T: Elevated levels of Rad51 recombination protein in tumor cells. Cancer Res 62: 219-225, 2002.

8. Hansen LT, Lundin C, Spang-Thomsen M, Petersen LN and Helleday T: The role of RAD51 in etoposide (VP16) resistance in small cell lung cancer. Int J Cancer 105: 472-479, 2003.

9. Vispe S, Cazaux C, Lesca C and Defais M: Overexpression of Rad51 protein stimulates homologous recombination and increases resistance of mammalian cells to ionizing radiation. Nucleic Acids Res 26: 2859-2864, 1998.

10. Slupianek A, Schmutte C, Tombline G, Nieborowska-Skorska M, Hoser G, Nowicki MO, Pierce AJ, Fishel R and Skorski T: $\mathrm{BCR} / \mathrm{ABL}$ regulates mammalian RecA homologs, resulting in drug resistance. Mol Cell 8: 795-806, 2001.

11. Slupianek A, Hoser G, Majsterek I, Bronisz A, Malecki M, Blasiak J, Fishel R and Skorski T: Fusion tyrosine kinases induce drug resistance by stimulation of homology-dependent recombination repair, prolongation of $\mathrm{G}(2) / \mathrm{M}$ phase, and protection from apoptosis. Mol Cell Biol 22: 4189-4201, 2002.

12. Bello VE, Aloyz RS, Christodoulopoulos G and Panasci LC Homologous recombinational repair vis-a-vis chlorambucil resistance in chronic lymphocytic leukemia. Biochem Pharmacol 63: $1585-1588,2002$

13. Maacke H, Jost K, Opitz S, Miska S, Yuan Y, Hasselbach L, Luttges J, Kalthoff $\mathrm{H}$ and Sturzbecher HW: DNA repair and recombination factor Rad51 is over-expressed in human pancreatic adenocarcinoma. Oncogene 19: 2791-2795, 2000.

14. Maacke H, Opitz S, Jost K, Hamdorf W, Henning W, Kruger S, Feller AC, Lopens A, Diedrich K, Schwinger E and Sturzbecher HW: Over-expression of wild-type Rad51 correlates with histological grading of invasive ductal breast cancer. Int J Cancer 88: 907-913, 2000

15. Han H, Bearss DJ, Browne LW, Calaluce R, Nagle RB and von Hoff DD: Identification of differentially expressed genes in pancreatic cancer cells using cDNA microarray. Cancer Res 62: 2890-2896, 2002.

16. Henning W and Sturzbecher HW: Homologous recombination and cell cycle checkpoints: Rad51 in tumour progression and therapy resistance. Toxicology 193: 91-109, 2003.

17. Yoshikawa K, Ogawa T, Baer R, Hemmi H, Honda K, Yamauchi A, Inamoto T, Ko K, Yazumi S, Motoda H, Kodama H, Noguchi S, Gazdar AF, Yamaoka Y and Takahashi R: Abnormal expression of BRCA1 and BRCA1-interactive DNA-repair proteins in breast carcinomas. Int J Cancer 88: 28-36, 2000.

18. Qiao GB, Wu YL, Yang XN, Zhong WZ, Xie D, Guan XY, Fischer D, Kolberg HC, Kruger S and Stuerzbecher HW: Highlevel expression of Rad51 is an independent prognostic marker of survival in non-small-cell lung cancer patients. Br J Cancer 93: 137-143, 2005

19. Brockstein B and Vokes EE: Concurrent chemoradiotherapy for head and neck cancer. Semin Oncol 31: 786-193, 2004.
20. Lingen MW, Chang KW, McMurray SJ, Solt DB, Kies MS, Mittal BB, Haines GK and Pelzer HJ: Overexpression of p53 in squamous cell carcinoma of the tongue in young patients with no known risk factors is not associated with mutations in exons 5-9. Head Neck 22: 328-335, 2000

21. Schliephake H: Prognostic relevance of molecular markers of oral cancer - a review. Int J Oral Maxillofac Surg 32: 233-245, 2003.

22. Koch W and Sidransky D: Molecular markers of radiation effectiveness in head and neck squamous cell carcinoma. Semin Radiat Oncol 14: 130-138, 2004.

23. Linke SP, Sengupta S, Khabie N, Jeffries BA, Buchhop S, Miska S, Henning W, Pedeux R, Wang XW, Hofseth LJ, Yang Q, Garfield SH, Sturzbecher HW and Harris CC: p53 interacts with hRAD51 and hRAD54, and directly modulates homologous recombination. Cancer Res 63: 2596-2605, 2003.

24. Yun S, Lie ACC and Porter AC: Discriminatory suppression of homologous recombination by p53. Nucleic Acids Res 32: 6479-6489, 2004.

25. Maacke H, Hundertmark C, Miska S, Voss M, Kalthoff H and Sturzbecher HW: Autoantibodies in sera of pancreatic cancer patients identify recombination factor Rad51 as a tumourassociated antigen. J Cancer Res Clin Oncol 128: 219-222, 2002.

26. Raderschall E, Bazarov A, Cao J, Lurz R, Smith A, Mann W Ropers HH, Sedivy JM, Golub EI, Fritz E and Haaf T: Formation of higher-order nuclear Rad51 structures is functionally linked to 21 expression and protection from DNA damage-induced apoptosis. J Cell Sci 115: 153-164, 2002.

27. Flygare J, Benson F and Hellgren D: Expression of the human RAD51 gene during the cell cycle in primary human peripheral blood lymphocytes. Biochim Biophys Acta 1312: 231-236, 1996.

28. Yamamoto A, Taki T, Yagi H, Habu T, Yoshida K, Yoshimura Y, Yamamoto K, Matsushiro A, Nishimune Y and Morita T: Cell cycle-dependent expression of the mouse Rad51 gene in proliferating cells. Mol Gen Genet 251: 1-12, 1996

29. Russell JS, Brady K, Burgan WE, Cerra MA, Oswald KA, Camphausen K and Tofilon PJ: Gleevec-mediated inhibition of Rad51 expression and enhancement of tumor cell radiosensitivity. Cancer Res 63: 7377-7383, 2003.

30. Sturzbecher HW, Donzelmann B, Henning W, Knippschild U and Buchhop S: p53 is linked directly to homologous recombination processes via RAD51/RecA protein interaction. EMBO J 15: 1992-2002, 1996.

31. Buchhop S, Gibson MK, Wang XW, Wagner P, Sturzbecher HW and Harris CC: Interaction of p53 with the human Rad51 protein. Nucleic Acids Res 25: 3868-3874, 1997.

32. Connell PP, Siddiqui N, Hoffman S, Kuang A, Khatipov EA, Weichselbaum RR and Bishop DK: A hot spot for RAD51C interactions revealed by a peptide that sensitizes cells to cisplatin. Cancer Res 64: 3002-3005, 2004.

33. Ohnishi T, Taki T, Hiraga S, Arita $\mathrm{N}$ and Morita T: In vitro and in vivo potentiation of radiosensitivity of malignant gliomas by antisense inhibition of the RAD51 gene. Biochem Biophys Res Commun 245: 319-324, 1998.

34. Ito M, Yamamoto S, Nimura K, Hiraoka K, Tamai $\mathrm{K}$ and Kaneda Y: Rad51 siRNA delivered by HVJ envelope vector enhances the anti-cancer effect of cisplatin. J Gene Med 7: 1044-1052, 2005.

35. Collis SJ, Tighe A, Scott SD, Roberts SA, Hendry JH and Margison GP: Ribozyme minigene-mediated RAD51 downregulation increases radiosensitivity of human prostate cancer cells. Nucleic Acids Res 29: 1534-1538, 2001.

36. Chen CF, Chen PL, Zhong Q, Sharp ZD and Lee WH: Expression of BRC repeats in breast cancer cells disrupts the BRCA2- Rad51 complex and leads to radiation hypersensitivity and loss of $\mathrm{G}(2) / \mathrm{M}$ checkpoint control. J Biol Chem 274: 32931-32935, 1999. 